\title{
A Win-Win Dual Internship Model for Turning Graduates Employable
}

\author{
Rajesh Subramanian, Aarthi Nagappan, Ivy Rose Mathew \\ Botho College, Botswana
}

\begin{abstract}
There seems to be a growing concern about the skill set needed in university graduates which is a factor inhibiting numerous students from acquiring proper employment. This has drawn the attention of employers and universities to work hand in hand to provide real time work exposure to students in developing the required skill set by way of internship. While most universities still follow the traditional method of offering single internship, Botho College, Botswana has gone an extra mile in introducing dual Internship for its students. This enables students to identify their lacking skills from their first internship experience and develop them through customized support sessions offered by the tutors. This is believed to prepare them for the second internship. Some employers also found that the interns on second internship were of better quality due to the impact of first internship and support sessions empowering them with the necessary employability skills. Most students also found this to help them in identifying an area for final year project and focus in developing the skills required to accomplish the project work and towards future job. It also enabled them to make future decision in terms of their career prospects and higher education. This article discusses on the impact of dual internship on academic performance and employability factor in University graduates. Authors believe from the lessons learnt that dual internship promotes both the employability and technical skills in students transforming them as well rounded graduates for immediate job market.
\end{abstract}

\section{Introduction}

Internship programs are introduced to offer students a real time work exposure in enabling to bridge the education - job skill mismatch, a major factor causing graduate unemployment. “...there have been many complaints from the private sector about the quality of graduates churned out by local private and public institutions [1]. However, there is a growing demand in the job market for qualified and skilled graduates. This has pressurized the HEIs to introduce initiatives to equip students with the necessary employability skills for immediate employment. Students in general acquire theoretical knowledge based on the classroom study but are not being given relevant industrial exposure and handson experience "Internships have been hailed for integrating classroom education with practical experience in enabling graduates to develop their professional knowledge and professional skills" [2]. Internships are gaining momentum and serve students in preparing for the job market. However, "Internships should not be considered as add-ons, but rather should be integrated into the academic program in order to optimize the learning opportunity" [3]. The best outside classroom learning activities are through an internship attachment [4]. Several studies have reported the benefits of internship programmes in conventional colleges and universities on the rationale in offering internship as part of the academic programme

Botho College is a leading multidisciplinary private tertiary institution in Botswana. It is on the forefront of bridging the employment divide between the employers and students. The college strives to imbibe certain essential qualities in the students so that they can provide an immediate contribution to any employer. The Intended Graduate Profile (IGP) is an employability profile which has been designed with the aim of producing graduates with certain degree of knowledge, skills and personal development needed to offer an immediate contribution to a prospective employer.

As a part of our focus on enhancing employability the college has developed an IGP internship programme. All our computing graduates are expected to undertake two mandatory internships of a minimum of 6 weeks and a maximum of 12 weeks each at the end of their second and third year of study respectively. The goal of the IGP internship is twofold:

1. Give students an appreciation of the relevance of their curriculum to the job market

2. To develop essential qualities or skills in students to make them employable

The IGP internship is a core module and is assessed just like any other modules. Students are expected to submit a 5000 words internship report which will be assessed. The grades obtained will be taken into consideration for the student to proceed to the next level. Guidelines for the internship report and assessment will be made available to the student and the tutor to ensure that mutual objectives are met.

Research highlighting the importance of relevant practical experience for students has been carried out [5] but the effects of these internships on the success of the intern to transfer the field practice into the 
actual workplace engagement needs follow up [6]

Whilst most universities have adopted traditional single internship model, Botho College with the introduction of dual internship model provides additional opportunity to its students in building upon their weakness areas. This happens through self learning, tutor feedback and participation in student support sessions after the first internship grooming them for second internship and final year project. Thus the programme supports for developing adequate knowledge and skills in students turning them employable.

Giving a second chance of internship to students offers several benefits. The students get one more opportunity to demonstrate the skills acquired through customized support sessions. It has helped students to improve on their academic performance, transformed their attitude towards work and study and improved professionalism. They also have acquired knowledge assisting them in making future decisions on final year project, higher studies and career. All of these benefits have increased the confidence level in students to meet the competitive world. "They assist the intern to bridge the gap between the academic learning process and the practical reality" [7][8].

'Cooperative education programs provide learning opportunities for students that enable them to integrate their work and their academic experiences'[9], hence it is important for a student to learn and imbibe qualities, skills that all employers look for. These attributes include enthusiasm, planning and organizing skills, time and stress management skills, communication skills, initiative and creativity, professionalism, work ethics. Some students have these skills naturally but most of the students need to develop them by way of internships and customized support sessions. Internship programs teach students how to resolve the problems on their own and at times interns also look out for advise or additional support from peers, tutor and internship supervisor. Apart from building interpersonal skills they also teach students on use of latest technologies and different media in real world making them aware of the available career choices to choose from for final year project and job.

The final year project is a capstone that will provide students with another opportunity to demonstrate gained knowledge and skills turning them from students to so called Industry ready graduates.

\section{Methodology}

The curriculum at Botho College has been re-designed to incorporate two mandatory internships which are at the second and third year of study respectively. This is followed by a project which needs to be done at the final year.

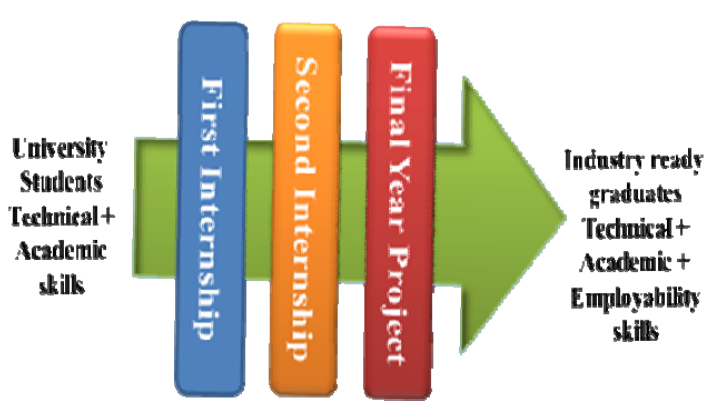

Figure 1. Inculcating work based skills in graduates

The figure 1 depicts the transformation of a university student into industry ready graduate by developing necessary skill set through undergoing dual internship and by doing the final year project .

\subsection{Stakeholders of the Internship Programme}

There are a number of stakeholders involved in the smooth running of the Botho college internship programme. Below figure 2 depicts various stakeholders involved in the process

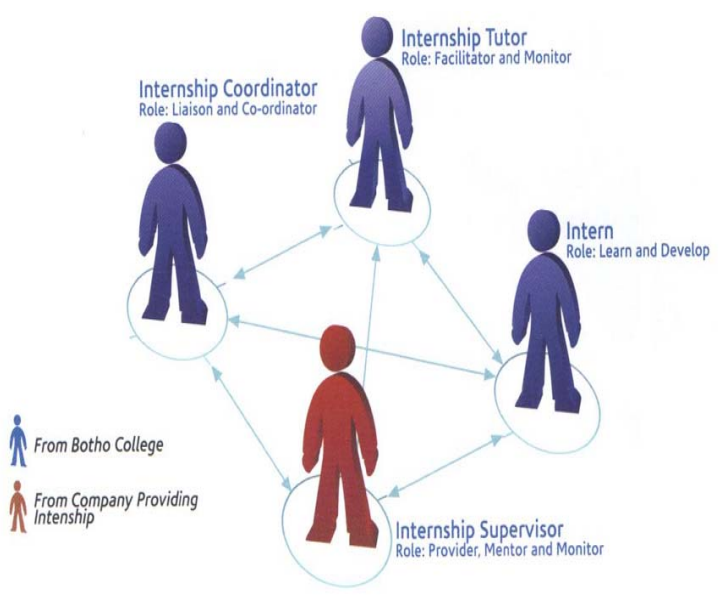

Figure 2 Stakeholders in internship programme

Intern: A student undergoing internship

Internship Tutor: Internal guide in the institution

Internship Coordinator: manages and coordinate the internship programme

Internship Supervisor: An external guide from the workplace

\subsection{Internship Programme:}

The internship tutors are identified at the 
beginning of the respective year of study. Each of these tutors are then assigned with a reasonable number of students (here after termed as intern) meeting the norm of tutor interns' ratio. The reason to adhere to the norm is to ensure quality guidance and timely feedback to interns enabling them to build on their capabilities and employability skills to meet the demands at the work place.

Every intern has the responsibility to arrange for his/her internship. S/he has to collect the internship request letter from the Career Services department of the college and submit it to various organizations looking for internship. The employer who is interested in offering the internship to the student will need to identify an external internship supervisor who would henceforth supervise the intern at workplace. This supervisor will need to confirm their interest to the college by means of filling the internship work plan. From the internship work plan the tutor will measure the relevance of internship being offered to student to their taught modules and may approve the offer or advise student accordingly on alternative options. Whilst some employer could reconsider and provide different role to their intern based on tutor's request, wherever this was not possible students were advised to look for another employer so that their studied areas could be put into practice. Those who are having difficulties in finding a suitable work place will be assisted by the internship coordinator.

The internship procedure requires the intern to be dedicated and to strictly follow the assigned deadlines for internship. The intern is not allowed to change the internship employer once the internship is confirmed by the internship tutor and external supervisor. The intern is also expected to submit weekly log report through mail to the tutor for feedback and attend all the scheduled monthly meetings apart from the frequent communication over email and phone.

The weekly log report is designed to enable the tutor to monitor the progress of the interns in a regular manner and to provide appropriate timely feedback to the intern to improve on their performance. A sample weekly log report template is shown below in Table 1

Table 1 . weekly log report

IGP Internship Weekly log report

Student Name :

Student ID :

Company Name:

Internship Location:

Internship Supervisor:

\section{Internship Tutor}

Period From : To

Date of Submission:

What new knowledge or skill did you learn during this week?

What have you learned in college that you applied in the internship

Describe any challenges that you encountered during this week. What did you do to overcome them?

Reflect on how could you have improved on your performance this week

Internship tutor comments:

The weekly log report with feedback is returned to the intern through email. The intern is advised to work on the feedback provided by the tutor for improved performance at the work place. In addition to the weekly feedback given to students, the tutor also gets to meet the interns at least once a month for a face to face interaction. These group meetings will enable interns to share and pick effective work practices from peers and their internship tutor. All the good suggestions emerging from the group meeting will be recorded by the tutor for future reference. These will also be disseminated to the other internship tutor's for improved guidance and advice to other interns.

It is also possible that some interns may be looking towards additional guidance and support 
from their tutor in order to cope up with the work in which case they are entertained to pay any number of visits, contact their tutor over phone or email. The tutor also establishes regular communication with external internship supervisor (who is a mentor and monitor at intern's workplace) over phone/email.

In addition to the above communication, the internship tutor will need to make onsite visits to discuss face to face with the external internship supervisor confirming on student's learning and developments while at work place. This gives an opportunity to the internship tutor to get exposed to the industrial requirements facilitating on improvised planning for the future internship activities

At the end of internship, each and every intern needs to review his/her work and submit the final internship report to the tutor as per the guidelines provided to them. This will be marked using a standard marking grid designed using the following assessment criteria

A. Introduction (Objectives and scope, Method of gathering the information) $20 \%$

B. Company's Background(Insight about the organisation, Role of the intern) 10\%

C. Findings (Description about the department, analyzing the IT infrastructure, SelfAssessment) $30 \%$

D. Reflections and Self appraisal (Implementation of learning, reflection on results, Communication skills) 30\%

E. Recommendation (Review and Suggestions for self improvement) $10 \%$

After carefully evaluating the interns on the above said criteria, an individual feedback would be shared with them. The intern is awarded a pass on successful completion of internship while other students will be provided with the resit/retake option based on their performance. These resit/retake interns will need to attend the support sessions offered by the experienced tutors in order to improve on their performance. On the other hand, there is also category of interns who managed to successfully complete internship at work place with good feedback but have failed because of the poor quality of document submitted. These interns will be given a chance to re-submit their newly written report to the tutor for consideration of a pass grade. This opportunity will be given to them after a scheduled session on improved document writing. This completes the first internship provided to a student.

Following up on the first internship, each and every intern was asked to perform a SWOT (Strength, Weakness, Opportunity and Threat) analysis and report on the findings to their respective tutors. This enabled the tutor to guide the intern to build up on the identified weakness areas. The feedback which the intern receives at each and every stage along with the experience from workplace helps them to improvise their capabilities and skills.

The authors also managed to discuss with few internship tutors to understand the outcome of the internship process, challenges faced and suggestions towards improvising the process.

In parallel a questionnaire was distributed to the intern's to seek their feedback on first internship experience and the questions are as below,

1. Was internship useful?

2. Did internship help you to develop your skills on communication, time management, stress management, team playing, conflict management and problem solving?

3. Would you like to be given another opportunity to do an internship?

4. If so, what are the areas you feel you need to improve on

5. Do you feel running support sessions prior to second internship would be helpful?

Analysis of the results from questionnaire and discussion with internship tutors paved way for running customized support sessions. These support sessions played a crucial role in building the lacking employability skills in students preparing them for the second internship and job. Hence it demanded effort on careful design and development of these sessions. The students are diverse and possess varied capabilities and lack on few skills which could be developed upon due attention. The support sessions have been designed keeping this in consideration and aimed at providing customized support to the students wherever possible. This molded the students for the second internship which they attended at the end of third year of study.

\subsection{Second Internship}

The students were asked to identify employers for their second internship. Some students managed to identify internship in their area of interest which demanded varied skills, of which some has been developed during the customized sessions with others still needing to be developed. The remaining students were to look out for employers sometimes maybe not in their area of interest. Those interns with good performance 
records managed to get back to their previous employer who was happy to have them back in the organization. The challenges were for the other students some of whom at last managed to find employer rest were assisted by Internship Coordinator from the Career Services department to obtain internship.

The study on second internship presented some interesting points to note. For those who successfully managed to find internship in their interested area were happy but soon realized their potential in the respective area and identified that there are skills which they needed to further develop to perform well in job. Other students either managed to return back to their previous employer or new employer for the second internship. Joining a new employer was presenting some challenges to students because of the initial learning curve problem prior to being put on work. However, for those of the students who were going for second internship to the same place as their first internship were finding it easy because of the familiarity and prior experience working in that place adding to their performance and work quality.

The second internship expected students to have acquired necessary employability skills before getting into the same. While some students had these necessary skills, others managed to develop them through the offered support sessions. Feedback from Interns made authors to believe that customized sessions had helped them acquire necessary skills. Thus the students became more prepared and trained before getting into the second internship. By the time of second internship students were also having a much clearer idea on their area of interest and career leading them to find the right employer in specific industry, unlike the first internship in which they were just finding some employer without much thought. However because of the limited industries in a country like Botswana, students were also finding it difficult to get internship in their area of interest.

During the second internship, the intern was expected to go for internship for a minimum period of 8 weeks. Here again the intern submitted the weekly log report to update the tutor about their weekly performance at workplace. This report assisted the internship tutor to regularly track the progress of the intern and recommend suggestions for improvement. In addition to this, students were meeting their tutor face to face at least once in a month. Cases where this was not possible because of a distant workplace, the students were advised to use technology for regular communication. Apart from this, the internship tutors also made visit to the interns' workplace twice during the course of internship .This enabled them to study the interns' behavior and performance. During this visit, they also conducted semi-structured interviews with the internship supervisor who was representing the employer.

At the end of this internship again, each intern will need to submit a final report to their tutor for evaluation. This document will be supported by the exit feedback provided by the external internship supervisor commenting on the interns' performance at workplace during internship. These will enable the tutor to judge the overall performance of intern during this internship and award him/her with appropriate grade.

Feedbacks have been taken from all the stakeholders concerned including employer, tutor and intern, to assist in the further improvement of the internship programme for future cohorts of students.

\section{Results and findings}

After return of students from first internship, an attitude survey was conducted with 506 interns to gauge the benefits of the internship and learning. Out of 506 total interns 433 participated in this first survey, out of which 57 questionnaires were partially filled. And 16 interns did not manage to hand in the questionnaire. The fully completed and returned questionnaires were alone considered for interpretation and data analysis. The summarized findings are stated below

Gender:

Male count : 252

Female count : 181

Age distribution:

Below 18: 7

$18-22$ : 253

$23-27: 168$

28 and above: 5

\section{Usefulness of internship:}

85\% felt the internship was useful

$31 \%$ felt they were not sure on whether internship added value to them

$4 \%$ felt the internship was not useful

\section{Capabilities acquired:}

Out of $79 \%$ of the intern who felt the internship was useful

57\% had improved on communication skills

43\% had improved on time management skills

23\% had improved on stress management skills

$69 \%$ had improved on working in team skills

$20 \%$ had improved on conflict management skills 
40\% had improved on problem solving skills

\section{Opting for dual internship}

Out of $100 \%$ of interns $86 \%$ said that they would like to be given another chance to do internship.

On the other hand $4 \%$ stated that single internship is sufficient while $10 \%$ was undecided.

Out of $86 \%$ of intern who opted for second internship

$46 \%$ felt needs to improve on communication skills

$37 \%$ felt needs to improve on time management skills

$42 \%$ felt needs to improve on stress management skills

$38 \%$ felt needs to improve on working in team skills

$25 \%$ felt needs to improve o n conflict management skills

43\% felt needs to improve on problem solving skills

\section{Helpfulness of Support sessions}

$67 \%$ of interns felt it will be helpful

$30 \%$ of interns felt they were not sure whether support session will be useful

$3 \%$ of interns felt it will not be helpful

The above statistical findings and analysis reveal that many interns found their internship to be useful and felt they had improved on certain skills and capabilities needed of the work place. They were eagerly looking forward to the support sessions to develop on their skills set. The lessons from the first internship experience along with customized support sessions assisted on demonstrating improved performance during their second internship. This also gave an opportunity to the interns to gauge themselves accurately on the employability scale. Based on the information sought from first survey, authors went ahead in organizing support sessions for the interns who are now currently on their second internship.

In the second internship, out of these 506 students most of them managed to arrange for their own internship however, others were supported by the internship coordinator in finding the internship. Generally, an exit feedback will be taken from the stakeholders at the end of the second internship in order to gauge the usefulness of the support session and the second internship. This in turn will be used to incorporate suggestions for the future cohort. However, due to a new cohort of students leaving for their second internship prior to the arrival of these current cohort interns from their second internship, there was a need to go in for an interim feedback with the stakeholders involved.

This interim feedback was taken in the form of a semi structured interview during the visit of the internship tutor to the interns' workplace. The interview with the external supervisor mainly focused on finding out the performance of the interns on their professional, social skills and work ethics while at work place. Some of the skills considered as part of the interview under the above mentioned three categories are as follows,

1. Professional skills
a. Productivity
b. Communication
c. Technical skills
d. Creativity

2. Social skills
a. Initiative
b. Interpersonal
c. Professionalism
d. Team Playing

3. Work Ethics
a. Punctuality
b. Reliability
c. Appropriate Attire
d. Work standards

Out of 506 interns who went for second internship, internship tutors managed to collect the feedback on the performance of 435 interns. However, only 417 of the forms were fully completed and hence were used in the following data analysis. The summarized findings are given below

The Figure 3 pie chart clearly depicts the performance of the interns under the three mentioned categories of skills. It has been noticed that the majority of interns have acquired the necessary social skills and work ethics need for the work place. However the improvements were needed on the dimension of the professional skills 


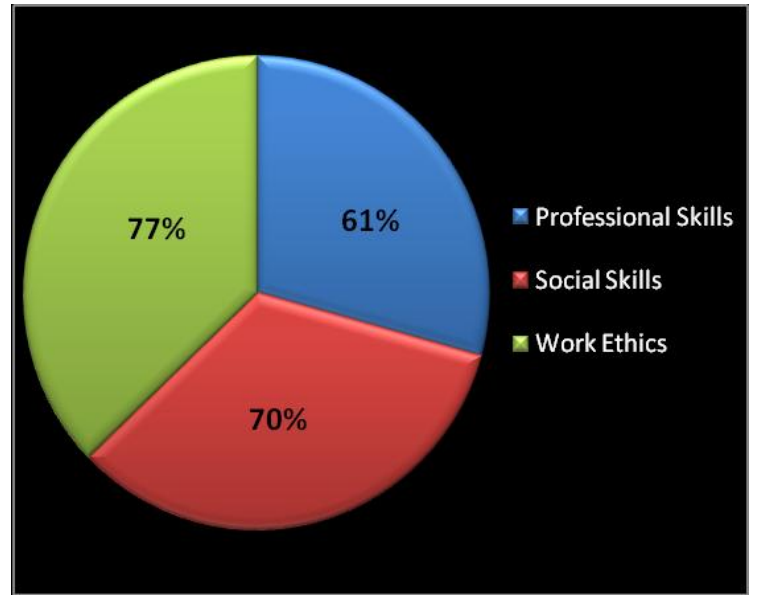

Figure 3 Performance measurement categories

The following figure 4 chart portrays the percentage of the different key performance factors associated with the professional skills development,

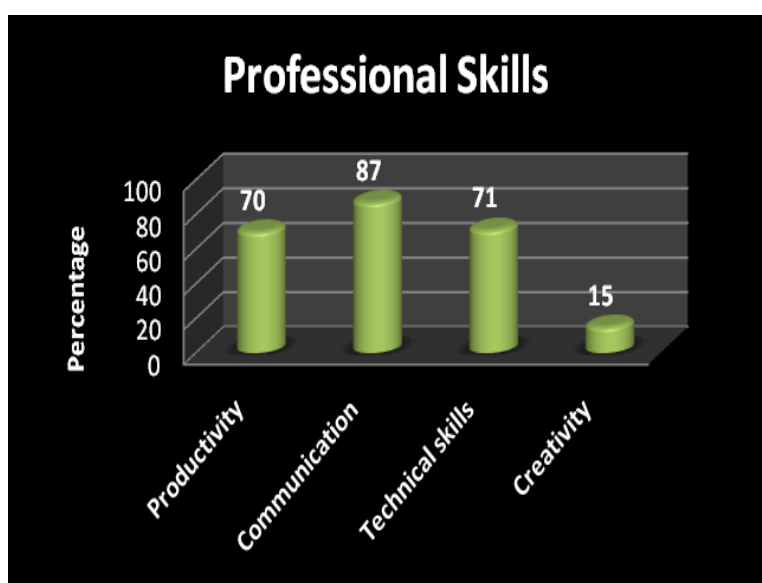

Figure 4 Professional skills performance factors

The very high rating found for the communication skills could be attributed to the support session given to students on the above area. The varied technical skills and expertise expected from different organizations may pose a challenge because of the curriculum which needs to be delivered within a limited time frame. This requires initiative from the part of the intern to learn and grasp the requirements of the job. The very low percentage for creativity was an indication for the authors to include in the future support sessions.

\section{Social Skills}

The figure 5 shows the social skills have improved compared to the first internship where most of the interns were now easily able to get along with their peers and work together as a team seeking guidance wherever required and demonstrating improved professionalism.

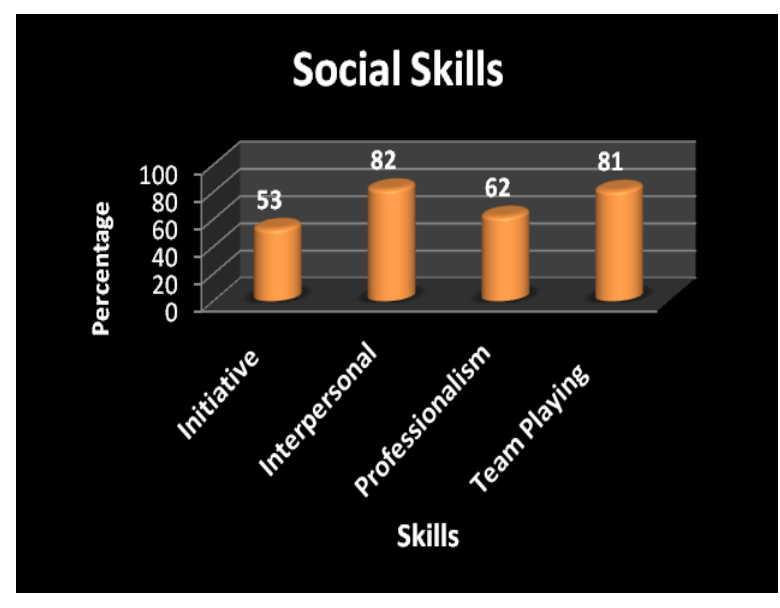

Figure 5 Social skills performance factors

\section{Work ethics:}

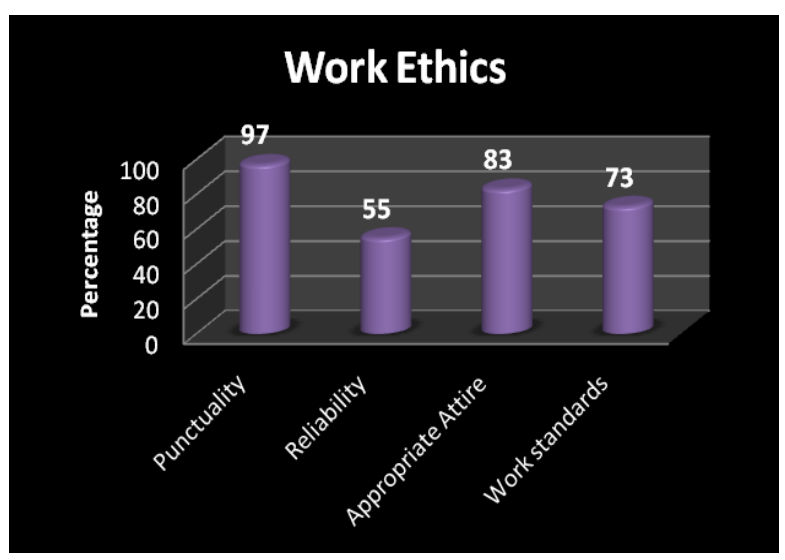

Figure 6 Work ethics performance factors

As shown in the figure 6, the external supervisors were very happy about the intern's work ethics. Several of them were commending on the punctuality and professional attire of the interns along with a note on improved work standards.

The above statistical analysis reveals that the interns are getting prepared with necessary skills to meet the demands of the job market. Apart from the discussion with external internship supervisor the internship tutor also managed to discuss with the interns to find out about the usefulness of the customized support sessions.

Interns very much appreciated the customized support sessions and dual internship in developing their skill set turning them more confident and prepared for upcoming final year project and job. They were more aware of the available career opportunities to make their future decisions and strongly recommended customized support sessions and dual internship for their juniors. The interns also felt that the support session should be extended for all students irrespective of whether they possess or lack the skills to avoid the embarrassment caused due 
to the discrimination among students. However it can be implemented based on the resource availability within the institution.

With so much valuable information sought in the form of feedback from external supervisor, intern and tutors. The discussion with other stakeholder namely Internship Coordinator brought to limelight the improved performance of interns who went to the same organization for first and second internship. These interns were able to easily get accommodated with colleagues, work place and were performing well because of the familiarity with workplace and skill set developed during customized support sessions. The below case study justifies the improved performance of interns who were with the same employer for both internship as against interns who worked with different employers during their internships.

We had some set of interns who managed to get the second internship in the same company where they went for their first internship. The experience and feedback on performance of 6 students who joined Land board, Mochudi for their second internship is discussed below.

Out of the 6 interns, 2 had the opportunity to work with this Land board assigning free lands to citizens for both their internships whilst 4 of them were new to this organization. It was reported by the employer that the quality of the interns in general were good during this second internship as compared against the first internship. And in particular, the 2 students who already worked with them during first internship were much more efficient in this second internship than their peers and acted as guides for the remaining 4 students who were new to the organization. These repeat interns demonstrated an improved leadership and management skills in addition to the other required skills. In general, second internship prepared most students on necessary employability skills turning them more employable.

This improved performance of repeat interns owing to familiarity of workplace and job was also commended much by the external supervisor especially for those students who did both their internships at the same workplace. Thus the dual internship assisted the interns on improving the employability skills needed for job market. It also contributed towards the attitudinal transformation in students enabling them to improve on other skills (i.e technical) and academic performance.

"research studies in accounting internships have shown improved subsequent academic performance"[10]. Below is a discussion on the performance of the students who have gone for the internship as against those who were not given an opportunity to go for internship. This was analyzed against the same cohort and a different cohort all together as shown in figure 7.

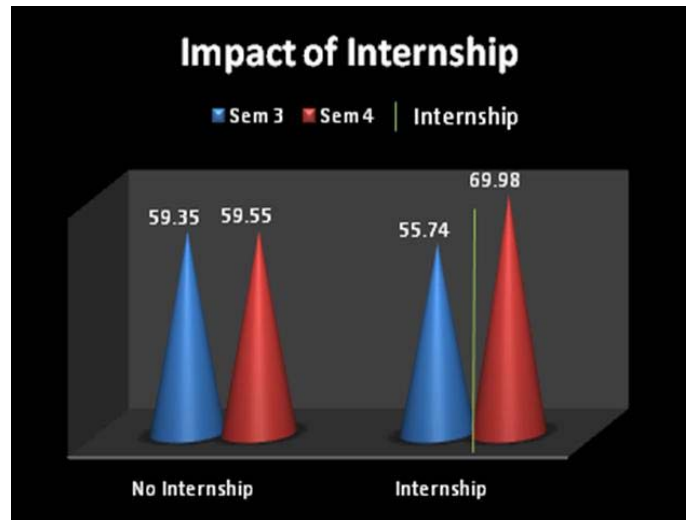

Figure 7 Impact of Internship

On the other hand, the performance of a cohort of students before and after their internship was also studied according to the stream/ specialization of study and discussed in figure 8 and figure 9 ,

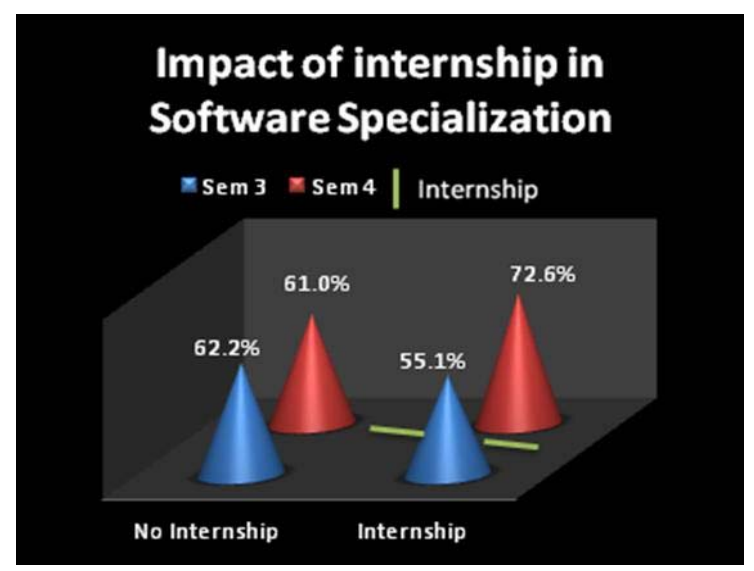

Figure 8 Impact in software specialization

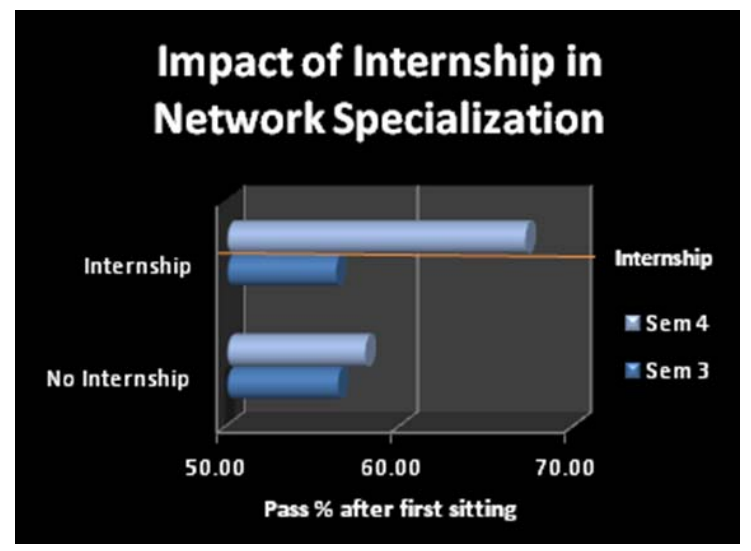

Figure 9 Impact in network specialization

The general feedback obtained was in favor of customized support sessions and dual internship in preparing students for job market. Employers also believed in internship to support organizations in establishing recruitment related decisions such as finding skilled candidates for vacant positions. The interim feedback taken also assured tutors that 
interns' performance during the second internship was far better than during the first internship. The second internship not only prepared the student on the employability skills but also on strengthening the technical skills that they would be requiring in completing the final year project. But then some organizations were also looking for an improvisation in skills such as planning and organizing, intercultural understanding, initiative, creativity and research skills which perhaps students may have failed to learn during the support sessions. The employers also came up with the suggestion to consider increasing the internship duration to assist students in having sufficient time to accustom and learn more about the work environment.

For the interns', they believe that the internship in general improved their work related skills. They also felt that this internship programme had helped them to get a supervised work experience and exposure to real time work atmosphere. They are even happy as some employers are now ready to absorb them for vacant positions. Similarly, some students claim to have been guaranteed the opportunity to do final year project with the same organization where they did their internship. These are indications of the benefits of dual internship to Botho College students.

In short, dual internship was a win - win situation for both interns and employer as some employers had free labor and interns' gained industrial exposure. This mutual benefit affirmed the concept of dual internship in bridging the gap between industry and academia. Thus, authors strongly recommend the programme of two internships with interspersed customized support sessions as a promising employability solution to other institutions for the benefit of student community and society in large hopefully seeing most if not all graduates employed immediately after their graduation.

\section{Conclusion}

This article reports on the impact of dual internship on improving academic performance and employment related skills in students and suggests it as a promising model to train and turn graduates ready for immediate employment. Internships expose students to work environment and enables them to understand self and their capabilities. This real world experience when supported by customized support sessions is well attended by the student owing to the attitudinal transformation resulting from their first internship. The second internship provides interns with another opportunity to demonstrate skills acquired through attending support sessions.

This dual internship though presents few challenges in the lines of available number of organizations for seeking internship, short duration of internship etc yet contributes a lot in developing employability skills, technical skills and improved academic performance. Whilst Internships inculcate work based learning in interns, the final year projects adds on the student's existing domain knowledge and skills and together creates well rounded graduates for employment.

The dual internship when introduced in universities should facilitate on improved graduate placement statistics and this could serve as a factor to boost student intake. Employers on the other hand, benefit from this trained industry ready graduates put to job immediately with minimum training hassles.

If every institution were to make sincere efforts in this direction, the country's vision of turning all graduates employable will soon become a reality from the so called dream.

\section{References}

[1]www.tec.org.bw/tec_doc/11_quality_of_loc al.pdf Quality of local graduates worries industry captains (accessed on 17.9.2011)

[2]Beard, D.F., (1998). The status of internship /cooperative education experiences in accountingeducation. Journal of Accounting Education, 16, 507-516.

[3]Patrick, C., Peach, D., Pocknee, C., Webb, F., Fletcher, M., and Pretto, G., (2009). The WIL Report: Work Integrated Learning - A National ScopingStudy. Brisbane, Australia. Australian Learning and Teaching Council (ALTC).

[4]Burnett, S. (2003). The future of accounting education: A regional perspective. Journal of Education for Business , 78, p. 129

[5]Mounce, P. H, Mauldin, D.S., \& Braun, R. L.(2004). The importance of relevant practical experience among accounting faculty: An empirical analysis of student' perceptions. Issues in Accounting Education 4.

[6]Beard, F. and Morton, L. (1999). Effects of internship predictors on successful field experience. Journalism \& Mass Communication Educator, 53, 42-53.

[7]Furco, A. (1996). Service Learning and Schoolto-Work. Journal of Cooperative Education , 1, 7-14. International Education Studies November, 200953

[8]Lam, T., Ching, L. (2007). An exploratory study of an internship program: The case of Hong Kong students.Hospitality Management, 26, 336-351.

[9]Weisz, M. \& Smith, S. (2005). Critical changes for successful cooperative education, in Higher 
education in a changing world, Proceedings of the 28th HERDSA Annual Conference, Sydney, 3-6 July 2005: 605-615.

[10] English, D.M. \& Koeppen, D.R. (1993). The relationship of accounting internship and subsequent academic performance. Issues in Accounting Education , Fall, 292-299 